\title{
Cutting balloon angioplasty and stenting for aorto-ostial lesions
}

\author{
Arvinder S Kurbaan, Paul A Kelly, Ulrich Sigwart
}

\begin{abstract}
Objective-To investigate the use of a cutting balloon to overcome aorto-ostial lesions before stent implantation and thereby reduce the restenosis rate.

Design-Observational follow up study.

Setting-Tertiary referral centre.

Patients-Eight patients (two female, six male) aged $58 \cdot 2$ (SD 10.1) years with Canadian Cardiovascular Society (CCS) grade II-IV angina were recruited. They each had a single target lesion (three in native coronaries, five in vein grafts).

Intervention and results-After high pressure angioplasty $(18(3 \cdot 8)$ bar), there was only a small reduction in the luminal stenosis, from $82(9) \%$ to $68(10) \%$, as assessed by on line quantative coronary angiography. However, using the cutting balloon there was a marked reduction in the luminal stenosis to 44 (15)\%, facilitating stent insertion. Subsequent high pressure dilatation resulted in a final stenosis of 10 (7)\%. At 6 (2) months' follow up the marked symptomatic improvement, to CCS angina grade 0 -II, was maintained and there were no further cardiac events or interventions

Conclusion-Cutting balloon angioplasty followed by stent insertion is a feasible technique for the treatment of aortoostial lesions, meriting further investigation.
\end{abstract}

(Heart 1997;77:350-352)

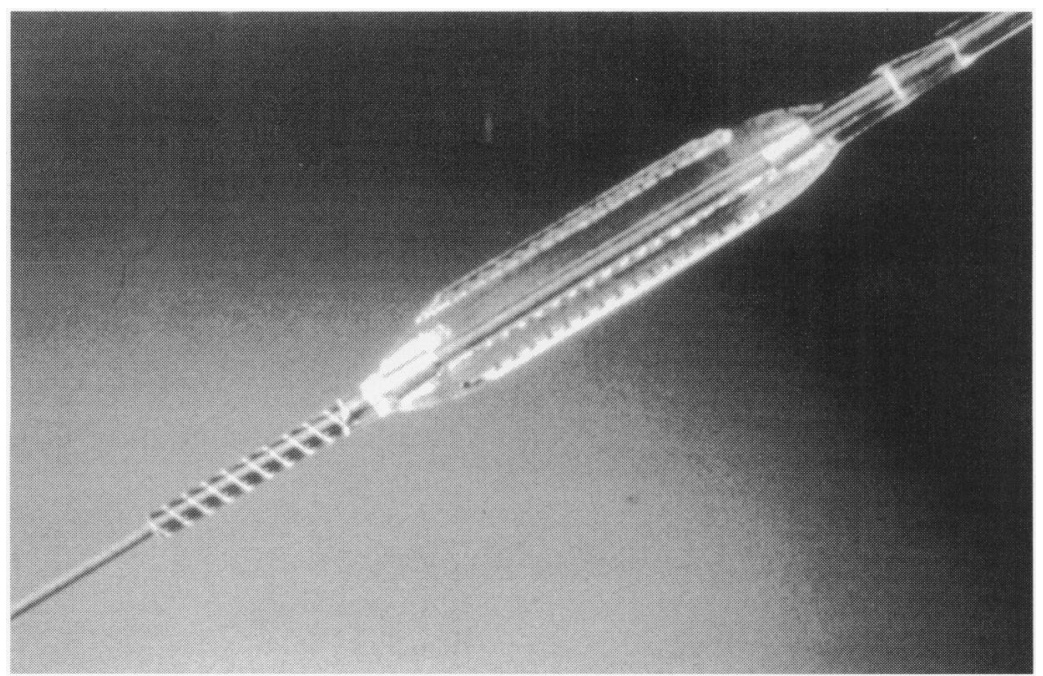

Figure 1 The cutting balloon: inflated profile.
Keywords: aorto-ostial lesions; stent; cutting balloon

Balloon angioplasty is an accepted revascularisation procedure for an expanding range of coronary artery diseases. ${ }^{1}$ Aorto-ostial lesions, either in native vessels or grafts, can be particularly difficult to dilate with conventional balloon angioplasty. Angioplasty of these lesions is further limited by the high restenosis rate. ${ }^{23}$ Attempts to overcome this problem with the use of laser based systems advanced over a guidewire or by rotational atherectomy have also been disappointing, particularly in terms of the restenosis rate. ${ }^{4}$ Results from stenting of both native and sapheneous vein grafts are encouraging. ${ }^{6}$ However, before a stent can be inserted an adequate postangioplasty luminal diameter is necessary to accommodate the unexpanded stent and delivery system.

Here we report eight cases of aorto-ostial lesions resistant to dilatation with conventional balloon angioplasty despite the use of high pressures, which were successfully dilated with the cutting balloon ${ }^{7}$ to facilitate the insertion of a stent.

\section{Methods}

The patients were selected after a conventional balloon angioplasty was unsuccessful in dilating the aorto-ostial stenosis, despite the use of high pressures of up to 22 bars.

\section{CUTTING BALLOON}

The cutting balloon is a balloon with three to four microsurgical blades $(0 \cdot 1$ to $0.4 \mathrm{~mm}$ thickness) mounted longitudinally on its surface (fig 1). Inflated nominal outer diameters range from 2.0 to $3.5 \mathrm{~mm}$ in $0.25 \mathrm{~mm}$ increments. Balloon length is either 10 or $15 \mathrm{~mm}$.

PROCEDURE

All procedures were performed through an $8 \mathrm{~F}$ guide catheter. An 0.014 ACS extra support guidewire was placed across the lesion and advanced well beyond the ostial stenosis. The vessel size was determined by on-line quantitative coronary angiography (QCA) and a conventional angioplasty balloon passed across the lesion and inflated to high pressure. If dilatation was not possible or minimal, this balloon was exchanged for the cutting balloon (Interventional Technologies, San Diego, USA), which was positioned at the site of the ostial stenosis and inflated. This produced longitudinal incisions in the wall of the vessel. The cutting balloon was then deflated, so that the atherotome cutting blades could be withdrawn safely 
into the balloon. The cutting balloon was then removed and exchanged for a stent delivery system (Johnson and Johnson Palmaz Schatz, ACS Multilink or Schneider Wallstent). An intracoronary stent was deployed at the site of the previous ostial stenosis and this was then inflated to high pressure with a short balloon ("Chubby", Schneider or ACS Finale). Throughout the procedure the activated clotting time was maintained between 300 and 400 seconds using heparin. Postprocedure treatment was ticlopidine $250 \mathrm{mg}$ twice daily for six weeks and aspirin 75 or $150 \mathrm{mg}$ daily. There was no anticoagulation with either heparin or warfarin after the procedure.

\section{Results}

Eight patients were recruited: six men and two women, aged 58.4 (SD 10.2) years. All the patients presented with angina, Canadian

Figure 2 Initial aortoostial lesion stenosis in saphenous vein graft.
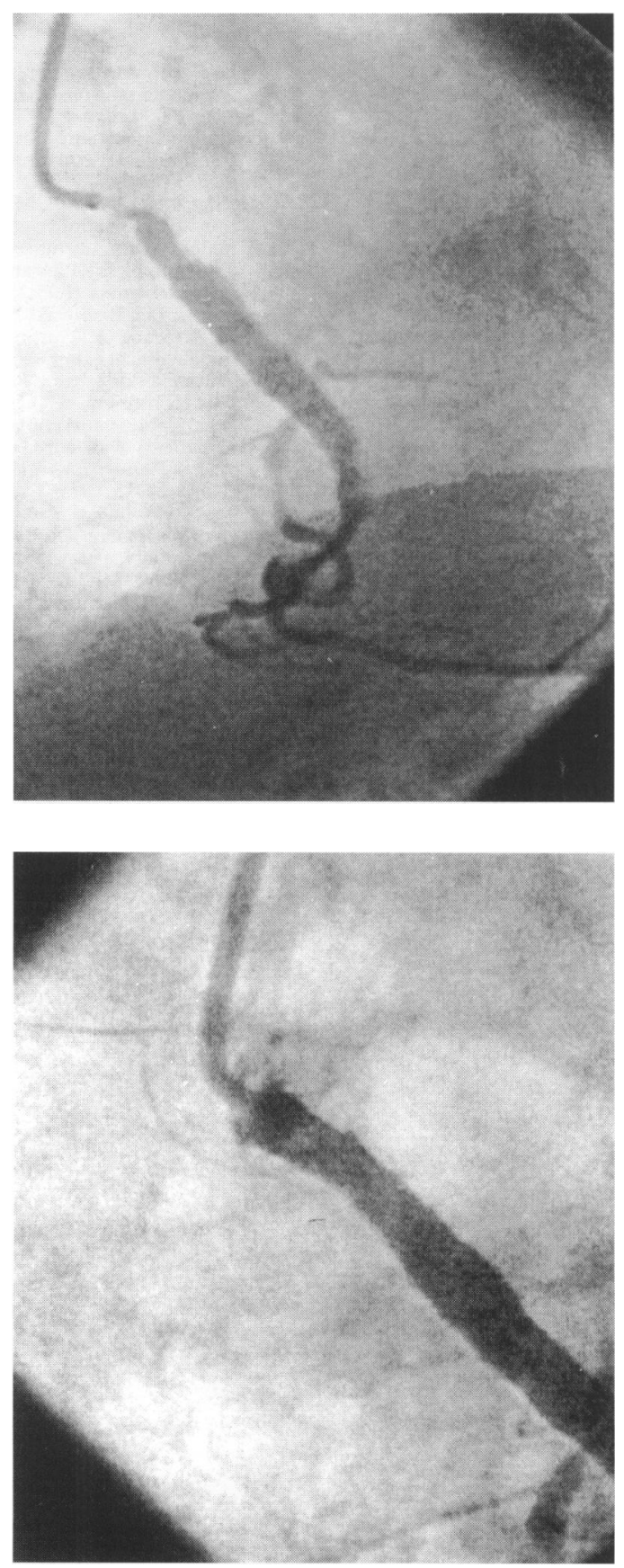

Cardiovascular Society (CCS) grade II-IV, with objective evidence of ischaemia (with either an exercise tolerance test or a thallium scan). Each patient had a single target lesion: three were native coronary artery lesions, five were sapheneous vein graft lesions. Patient 7 , with a right coronary ostial stenosis, had received radiotherapy to the chest 20 years earlier and had no other significant coronary disease. The others were presumed to have atherosclerotic disease.

The initial target stenoses were 82 (9)\% (fig 2). After high pressure balloon dilatation (18 (3.8) bar) the residual target stenoses were 68 (10)\%. Using either the $3 \mathrm{~mm}$ or the $3.5 \mathrm{~mm}$ diameter cutting balloon, at pressures of $7 \cdot 5$ $(0.5)$ bar the residual stenosis was reduced in all the cases, to $44(15) \%$. This facilitated stent deployment and further high pressure inflation (14.6 (1.6) bar) within the stent. A successful result was achieved in all cases. The final procedure residual stenoses were $10(7) \%$ (fig 3). In all cases the procedure was successful, without any complications during or after it. Patients were discharged within the next 24 hours.

At 6 (2) months' follow up, all patients had a marked improvement in their symptoms. All had CCS grade 0 or I angina, except one who had grade II. Although it was not indicated clinically, two patients had angiography at six months postprocedure. Patient 4 had a residual luminal stenosis of $20 \%$ and patient 5 of $26 \%$. There were no deaths, infarctions, or need for further revascularisations in any of the patients during this follow up period.

\section{Discussion}

DILATATION OF AORTO-OSTIAL LESIONS

Conventional balloon dilatation can successfully dilate the majority of coronary artery stenoses. However, despite the use of high balloon pressures aorto-ostial lesions have a low primary success rate, a high complication rate, and a high incidence of restenosis. This may be as a result of the simultaneous presence of atherosclerosis, fibrosis, and calcification in the surrounding aortic wall, and the higher concentration of elastic and muscle fibres around the ostium, which causes recoil after balloon inflations. Hence these lesions appear to be both rigid and elastic at the same time. Various strategies have been devised in an attempt to overcome this problem. Excimer laser coronary angioplasty has a high initial angiographic and clinical success rate but restenosis remains a limitation. ${ }^{4}$ Similarly, although, rotational or transluminal extraction atherectomy is associated with high procedural success rates and a low incidence of complications, the restenosis rate remains high. ${ }^{5}$ The beneficial action of stents has been attributed to maximising the initial luminal gain and overcoming the elastic recoil ${ }^{89}$ - these mechanical advantages may be ideally suited to aorto-ostial lesions. Stent insertion into sapheneous vein graft aorto-ostial lesions is associated with a high procedural success rate. The long term follow up is comparable to 
stents inserted into the body of the vein graft. ${ }^{6}$ However, stent insertion requires an adequate luminal diameter postangioplasty. In our cases dilatation with the cutting balloon enabled sufficient luminal gain to be obtained, facilitating stent insertion. This combination resulted in a good postprocedural result with no immediate or late complications.

\section{MECHANISM OF ACTION OF THE CUTTING BALLOON}

It has been postulated that the mechanism of balloon angioplasty action involves three events: plaque fracture, compression, and stretch. ${ }^{10}$ Balloon dilatation within a stenosis results in application of force in a random manner to the components of the stenosis. Because of the vessel-balloon geometry, much of the force of the balloon inflation is converted to circumferential shear stress, which results in multiple arcs of dissection, rather than radially directed fissures. The presence of the longitudinal blades on the cutting balloon has two potential benefits. ${ }^{11}$ First, the blades concentrate the dilatation force, enabling more resistant stenoses to be overcome-it is of note that the lesions failed to dilate with conventional balloon angioplasty despite the use of pressures up to 22 bar. Second, it is possible that a more organised approach to plaque disruption due to the alignment of the blades could produce the desired increases in luminal cross sectional area without creating the extensive intraplaque disruption that the randomly applied force of regular balloon angioplasty produces. This may reduce restenosis and improve long term outcome. ${ }^{12}$

\section{PRACTICAL PERSPECTIVE}

From a practical perspective there is no need for exchange of guidewires, further operator training, or expensive additional technology.

\section{STUDY LIMITATIONS}

This is only an observational study involving a small number of patients. Ideally the technique should be tested against competing strategies for aorto-ostial lesions in a prospective randomised trial. Although complete clinical follow up is available showing that the patients had all maintained their initial improvement in symptoms, there is angiographic follow up in only two cases.

\section{CONCLUSION}

The cutting balloon proved useful in dilating stenoses resistant to conventional balloon dilatation alone and so facilitating insertion of a stent and perhaps improving long term outcome.

1 Detre K, Holubkov R, Kelsey S, Cowley M, Kent K, Williams $\mathrm{D}$, et al. Percutaneous transluminal coronary angioplasty in 1985-1986 and 1977-1981: the National Heart, Lung, and Blood Institute Registry. $N$ Engl f Med Heart, Lung, and

2 Topol EJ, Ellis SG, Fishman J, Leimgruber P, Myler RK, Stertzer SH, et al. Multicenter study of percutaneous transluminal angioplasty for right coronary artery ostial stenosis. F Am Coll Cardiol 1987;9:1214-18

3 De Feyter PJ, Van Suylen RJ, De Jaegere P, Topol E, Serruys PW. Balloon angioplasty for the treatment of lesions in saphenous vein grafts. $\mathcal{F}$ Am Coll Cardiol 1993; 21:1539-49.

4 Eigler N, Weinstock B, Douglas JS, Goldenberg T, Hartzler G, Holmes D, et al. Excimer laser coronary angioplasty of aorto-ostial stenoses: results of excimer laser coronary angioplasty (ELCA) registry in the first 200 patients. Circulation 1993;88:2049-57.

5 Koller PT, Freed M, Grines CL, O'Neill WO. Success, complications and restenosis following rotational and transluminal extraction atherectomy of ostial stenoses. Cathet Cardiovasc Diagn 1994;31:255-60.

6 Rechevia E, Litvack F, Macko G, Eigler N. Stent implantation of saphenous vein graft aorto-ostial lesions in patients with unstable ischemic syndromes: immediate
angiographic results and long-term clinical outcome. $f$ Am Coll Cardiol 1995;25:866-70.

7 Unterberg C, Buchwald AB, Barath P, Schmidt T, Kreuzer $\mathrm{H}$, Wiegand A. Cutting balloon coronary angioplastyH, Wiegand A. Cutting balloon coronary angioplasty-

8 Serruys PW, de Jaegere P, Kiemeneiji F, Macaya C, Rutsch W, Heyndrickx G, et al. A comparison of balloon expandable stent implantation with balloon angioplasty in patients with coronary artery disease (The Benesten study). N Engl F Med 1994;331:489-95.

9 Fischman DL, Leon MB, Baim DS, Schatz RA, Savage $\mathrm{MP}$, Penn I, et al. A randomized comparison of coronary stent placement and balloon angioplasty in the treatmen of coronary artery disease (The Stress trial). $N$ Engl $f$ Med 1994;331:496-501.

10 Lorsado D, Rosenfield K, Pieczek A, Baker K, Harding M, Isner J. How does angioplasty work? Serial analysis of human iliac arteries using intravascular ultrasound. Circulation 1992;86:1845-58.

11 Barath P, Fishbein MC, Vari S, Forrester JS. Cutting balloon: a novel approach to percutaneous angioplasty. $\mathrm{Am}$ f Cardiol 1991;68:1249-52.

12 Stillabower ME. Longitudinal force focused coronary angioplasty: a technique for resistant lesions. Cath Cardiovasc Diagn 1994;32:196-8. 